\section{SUXAMETHONIUM (SUCCINYLCHOLINE) CHLORIDE AND MUSCLE PAINS}

\author{
BY
}

\section{H. C. CHURChILL-DAVIDSON, M.D., D.A. \\ Late Senior Registrar, Department of Anaesthetics, St. Thomas's Hospital, London}

In normal human subjects both decamethonium and suxamethonium salts act by depolarization, the onset of paralysis being preceded by a momentary period of stimulation which is often visible as muscle fasciculations throughout the body. Conscious volunteers have often noted the characteristic tight feeling in the jaw and calf muscles that may persist for 12 to 24 hours after an injection of decamethonium (Organe et al., 1949 ; Churchill-Davidson and Richardson, 1952). An investigation has been carried out to determine whether similar muscle pains follow the injection of suxamethonium.

\section{Method}

For this investigation the patients were divided into two groups. Group I comprised those out-patients undergoing minor operative procedures necessitating a general anaesthetic and muscular relaxation-that is, bronchoscopic and laryngeal investigations. Group II was identical with Group I except that the patients were confined to hospital for at least 48 hours after the operation.

On the second post-operative day each patient was asked to complete Form 1.

FORM 1

1. Were you able to return to work the next day? If the answer is "no," would you please give the reason.

2. Did you sleep well the night after the examination?

3. Did you have any pain or weakness in your muscles the following day? If the answer is "yes," would you please give as many details as possible.

4. Did you have any headache following the examination? If so, for how long?

Questions 1, 2, and 4 were included merely for padding. If the answer to question 3 was "Yes" the patients were asked to complete Form 2 on the fourth post-operative day.

\section{FORM 2}

(a) When did the first pain occur ? (E.g., that evening, next morning, afternoon, etc.)

(b) Where did you first notice it? (E.g., all over the body, in neck, or in legs, etc.)

(c) Is it similar to any other pain you have experienced ? (E.g., cramp, stiffness, pins and needles, etc.)

(d) How long did it last ? (E.g., one hour, six hours, one day, three days, etc.)

(e) Did anything make it worse or better? (E.g., improved on exercise or improved on resting.)

Premedication.-The patients in both groups were given papaveretum hydrochloride, $10 \mathrm{mg}$., and hyoscine hydrobromide, $0.425 \mathrm{mg}$., except those over 60 years of age, who were given $10 \mathrm{mg}$. of papaveretum hydrochloride and $0.6 \mathrm{mg}$. of atropine sulphate.

Anaesthesia was induced with $0.3-0.5 \mathrm{~g}$. thiopentone sodium (mean dose, $0.46 \mathrm{~g}$. in group I and $0.42 \mathrm{~g}$. in group II), followed by $30-150 \mathrm{mg}$. suxamethonium (mean dose, $88 \mathrm{mg}$. in group $\mathrm{I}$ and $96 \mathrm{mg}$. in group II).

Age Incidence.-Each group was selected at random. The average age in group I was 58 years and in group II 64 years.

\section{Results in Group I (Out-patients)}

Of 32 cases examined, 21 (66\%) developed muscle pains on the day after the operation, and in two-thirds of these 21 cases the pains appeared to be of a severe and incapacitating nature (Table 1).

Table I.-Details of Muscle Pains Present in 21 (66.7\%) Out of 32 Cases Examined

Site: Generalized, $13(61.9 \%)$; legs and arms, 6 (28.6\%); subcostal region only, $2(9.5 \%)$.

Description: "Stiffness," 14 (66.7\%); " weakness," 4 (19\%) "rheumatic," $3(14.3 \%)$

Duration: 4 days, $3(14.3 \%) ; 3$ days, 7 (33.3\%); 2 days, 8 $(38.1 \%): 1$ day, $3(14.3 \%)$.

Severity: Severe. $14(66.7 \%)$ : moderate, $2(9.5 \%)$; mild, $5(23.8 \%)$.

Relief: By exercise, $14(66.7 \%)$; by rest, 7 (33.3\%).

The severity of these muscle pains following suxamethonium is best emphasized by brief reference to three case histories.

Case A.-A conscious volunteer subject was given $10 \mathrm{mg}$. of suxamethonium intravenously. A brief period of skeletal muscle paralysis ensued (approximately 3 minutes 20 seconds). Recovery was rapid and complete. No further trouble was experienced until on rising the following morning, when he felt a generalized stiffness with a painful sensation in the subcostal and retrosternal region. The stiffness gradually receded during the day, but the subcostal pain persisted for a further two days.

Case B.-A woman aged 26 attended hospital as an outpatient for bronchoscopy following a persistent $x$-ray shadow at the base of the left lung. She was anaesthetized with $0.4 \mathrm{~g}$. of thiopentone sodium and $100 \mathrm{mg}$. of suxamethonium. Three hours later (5 p.m.) she left hospital feeling well, and during the rest of the evening was able to carry out her normal household duties. On awakening next morning, however, she was hardly able to move her arms or legs, and had to be assisted into the upright position. There was only slight improvement throughout the day. Next day she stated that her legs still felt too weak to stand, and she was brought to hospital in an ambulance. On examination the range of passive movement in the limbs was almost complete, apparently being only slightly limited by pain. Reflex activity and sensation were normal. There was marked reduction in active movement, particularly in the lower limbs, with some tenderness on pressure of the muscles.

Case C.-A man aged 67, with carcinoma of the bronchus, was anaesthetized with $0.4 \mathrm{~g}$. of thiopentone and $90 \mathrm{mg}$. of suxamethonium for bronchoscopy. Next day he was well and left hospital in the afternoon. As he was climbing the stairs of his home his legs felt painful and weak. This persisted to such a degree that he was readmitted to hospital the same evening, although no cause for the weakness could be found.

Comment.-Cases B and C clearly showed a certain accompanying psychological element, but in the light of the evidence presented in Table I they cannot be dismissed as hysterical. Some of the patients described their condition with such phrases as "unable to move next day," "lost strength in all muscles," and "ached all over," to mention but a few.

\section{Results in Group II (In-patients)}

Of 36 patients examined, only $5(13.9 \%)$ complained of muscle pains, and full details of these pains are shown in Table II. It is interesting to note that of the five patients who complained of muscle pains three had been permitted to leave their bed either on the same night or on the follow-

TABLE II.-Details of Muscle Pains Present in 5 (13.9\%) of 36 Cases Examined

Site: Generalized. $1(20 \%)$; legs and arms, 2 (40\%); subcostal, 2 $(40 \%)$.

Description: Stiffness $5(100 \%)$.

Duration: 3 days, $1(20 \%) ; 2$ days, $3(60 \%) ; 1$ day or less, 1 $(20 \%)$.

Severity: Severe, $1(20 \%)$; moderate, 0 ; mild, $4(80 \%)$. 
ing day. If, therefore, only those patients who remained at rest are included, the incidence of muscle pains in this group is $5.6 \%$-that is, 2 patients out of 36 examined.

\section{Trial with Gallamine}

In order to determine whether the abolition of visible muscle fasciculations prevented the muscle pains following suxamethonium a further series was attempted identical with group I (out-patients) except that the injection of suxamethonium was preceded by $40 \mathrm{mg}$. of gallamine triethiodide. This abolished visible twitching in every case. Of 15 cases examined, $6(40 \%)$ complained of muscle pains. The significance of results based on such a small series is difficult to analyse, but the general impression was that following gallamine the incidence and severity of the muscle pains were diminished, though with this dosage they were not abolished. Further support is given to this suggestion by the finding in 12 in-patient cases (that is, confined to bed for 48 hours after operation), that if a dose of gallamine triethiodide $(80 \mathrm{mg}$.) was given before the administration of suxamethonium there was no case of post-operative muscle stiffness.

\section{Discussion}

Suxamethonium has been widely used as a short-acting muscle relaxant in both clinical surgery and electric convulsion therapy. If it is given, however, to patients who are not confined to bed after treatment it may be followed by a degree of incapacity out of all proportion to the severity of the procedure. Severe stiffness can develop on the first day after operation, which has been likened to the muscle stiffness that of ten follows some violent physical exercise. If, on the other hand, the use of suxamethonium is confined to patients resting in bed the incidence of muscle pains is low.

It has been shown in man that decamethonium iodide causes muscle activity of apparent motor unit origin (Churchill-Davidson and Richardson, 1952) as opposed to single muscle-fibre potentials which might be anticipated from the use of a depolarizing drug. It has been suggested (Paton, 1952) that this fascicular twitching is due to centripetal antidromic impulses in the motor nerve axon bringing about a synchronous discharge of the whole motor unit (Masland and Wigton, 1940). The finding that gallamine triethiodide prevents the muscle fasciculations of suxamethonium but only reduces the incidence of " after-pains" suggests that these pains may not be due to the vigorous twitching of the muscles but to some curious association of depolarization by succinylcholine and normal muscular activity.

Suxamethonium, therefore, has two serious disadvantages. First, in company with all depolarizing drugs it has no satisfactory antidote, and the occasional case of prolonged action still occurs (Bourne, 1953; Evans et al., 1952). Secondly, it is unsuitable for use as a muscle relaxant for out-patient procedures, because it may be followed by severe muscle stiffness.

Decamethonium enjoyed only a brief span of popularity in clinical surgery. It would seem that the longevity of suxamethonium must depend upon the time it takes to find a new muscle relaxant of brief effect acting by competitive inhibition (like D-tubocurarine chloride) but destroyed by plasma cholinesterase. In the event of a prolonged action neostigmine could then be given with confidence.

\section{Summary}

When suxamethonium is used as a short-acting muscle relaxant for out-patient procedures it is followed next day in a large proportion of cases by muscle pains and stiffness, the severity of which is out of proportion to that of the minor operation. These pains commonly persist for two to three days. The incidence in patients confined to bed is low.
The abolition of the fascicular twitching - a notable feature after the injection of suxamethonium-reduced the incidence and severity of the muscle pains.

The value of suxamethonium as a short-acting muscle relaxant is briefly discussed.

I am most indebted to Drs. Regina Mackay and David Chandler for their help in following up these cases, and to all the members of the department of anaesthetics who co-operated so generously. Miss Jean Davenport gave invaluable secretarial assistance.

\section{REFERENCES}

Bourne, J. G. (1953), Brit. J. Anaesth., 25, 116. 252 . Proc. roy. Soc

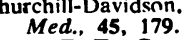

Evans. F T., Gray, P. W. S. Lehmann, H., and Silk, E. (1952). Lancet. 1. 1229.

Masland. R. L., and Wigton. R. S. (1940). J. Neurophysiol., 3. 269. W D. $M$ and Zaimis, E. J. (1949). Lancet, 1, 21 Paton, W. D. M. (1952). Proc. roy. Soc. Med., 45, 186.

\section{ACUTE TOXIC HYPOGLYCAEMIA IN THE VOMITING SICKNESS OF JAMAICA}

\author{
BY \\ D. B. JELLIFFE, M.D., M.R.C.P., D.C.H. \\ D.T.M.\&H. \\ AND
}

\section{K. L. STUART, M.D., M.R.C.P., M.R.C.P.Ed. D.T.M.\&H.}

(Department of Medicine, University College of the West Indies, Mona, Jamaica)

The illness at present known as the vomiting sickness of Jamaica has a distinct clinical picture, which has been reviewed by Hill (1952). It occurs sporadically or in small, usually family, outbreaks during the colder winter months, when food is relatively scarce amongst the Jamaican peasant population. The onset is dramatically sudden, often with severe vomiting, followed by rapid prostration with a low blood pressure and tachycardia; the temperature is not elevated and diarrhoea does not occur. This may be followed by a latent period of apparent improvement lasting a few hours or may pass direct into the terminal phase of drowsiness, twitching, convulsions, and coma-sometimes associated with effortless vomiting. There is a high mortality, death occurring on an average after 12 hours. Cases that recover do so completely.

A fulminating clinical variant is also recognized in which no vomiting occurs, the illness presenting with spectacular abruptness, with sudden collapse, drowsiness, convulsions, stupor, twitching of the limbs, coma, and death. The whole episode may last only a few hours.

The syndrome usually occurs against a background of poverty and subnutrition, and those affected are often, but not always, underweight and frequently show signs of slight deficiency of the vitamin-B complex and protein - such as angular stomatitis, glossitis, mosaic skin, and hypochromotrichia. Families are often involved, the main incidence being in children of 3 to 10 years.

As has been stressed by Cicely Williams (1953) and Chambers (1953), a diagnosis of vomiting sickness is often loosely used in Jamaica to cover various undiagnosed illnesses in which vomiting or sudden death has occurred. Nevertheless, after taking this into account, there remains a definite group of typical cases showing a characteristic clinical picture. 